\title{
IMPROVING AIR QUALITY IN COMMUNITIES BY USING A MULTICRITERIA DECISION-MAKING MODEL BASED ON BIG DATA: A CRITICAL REVIEW
}

\author{
HSUEH, S. L. ${ }^{*}-$ CHENG, A. C. \\ Graduate Institute of Cultural and Creative Design, TungFang Design Institute \\ No.110, Dongfang Rd., Hunei Dist., Kaohsiung City 82941, Taiwan \\ *Corresponding author \\ e-mail: hsueh.sl@msa.hinet.net; tel: +86-9-32-883-292; fax: +86-7-693-9663 \\ (Received $12^{\text {th }}$ Aug 2016; accepted $15^{\text {th }}$ Nov 2016)
}

\begin{abstract}
Information technology has advanced rapidly and has long been used in various fields and industries. The accumulated data are valuable in practical applications related to topics, such as scientific research, commercial development, and policy-making references. Recent global climate anomalies are due to the ongoing reclamation and extensive use of natural resources in the ongoing process of human evolution and development. Demand for industrial development and economic competition among countries have caused high $\mathrm{CO}_{2}$ emissions, which is becoming a severe problem. Through analyzing relevant big data, people can explore the causes of high $\mathrm{CO}_{2}$ emissions and propose effective solutions. Factors contributing to high $\mathrm{CO}_{2}$ emissions not only include the strong dependence on energy and its use in economic, industrial, and commercial development, but families and individuals also contribute to air pollution. To solve this problem, this study investigated topics on public policy issues involving big data, community education effectiveness, and low-interest loans. In addition, this study adopted the Delphi method, analytical hierarchy process, and fuzzy logic theory to establish a multicriteria decision-making model based on big data to evaluate the processes of reducing air pollution in urban areas. Because community education contributes to resolving public policy problems, the proposed MCDM model enables researchers to determine improvements in urban air quality and aids in discerning the effects of community education on the promotion of environmental protection policies. In addition, this study proposed methods involving grants and low-interest financing to enhance improvements.
\end{abstract}

Keywords: carbon dioxide, public policy issues, Delphi method, AHP, Fuzzy logic theory, community education

\section{List of abbreviations}

AHP analytical hierarchy process

APEC Asia-Pacific Economic Cooperation

CDIAC Carbon Dioxide Information Analysis Center

CEO chief executive officer

CI consistency index

$\mathrm{CO}_{2} \quad$ carbon dioxide

CR consistency ratio

DFuzzy Delphi - fuzzy logic theory

DAHP Delphi - analytical hierarchy process

FLIS fuzzy logic inference system

LED light-emitting diode

MCDM multi-criteria decision making 


\section{Introduction}

The United Nations Framework Convention on Climate Change (UNFCCC) was signed in 1992, and the related Kyoto Protocol was signed in 1997. However, total global $\mathrm{CO}_{2}$ emissions not only remain high, but have exhibited an increasing trend annually. $\mathrm{CO}_{2}$ concentrations in the atmosphere have increased from $310 \mathrm{ppm}$ in 1960 to over $400 \mathrm{ppm}$ as of 2015 (Fig. 1). After paying considerable attention to the problem of $\mathrm{CO}_{2}$ emissions, European countries have achieved a considerable decrease in emissions each year, as has the United Stated in recent years. In other countries, however, $\mathrm{CO}_{2}$ emissions continue to rise, particularly in China and India, where the economies are growing rapidly. Figure 2 depicts the $\mathrm{CO}_{2}$ emissions in China and other major countries (Liu, 2015). Whether atmospheric $\mathrm{CO}_{2}$ concentrations can be reduced to less than $300 \mathrm{ppm}$, as it was before 1960, depends on every country's effort in effectively reducing the use of gasoline, coal, and natural gas. Concurrently, it also depends on the development of low-carbon clean energies to mitigate the steadily increasing atmospheric $\mathrm{CO}_{2}$ concentrations.

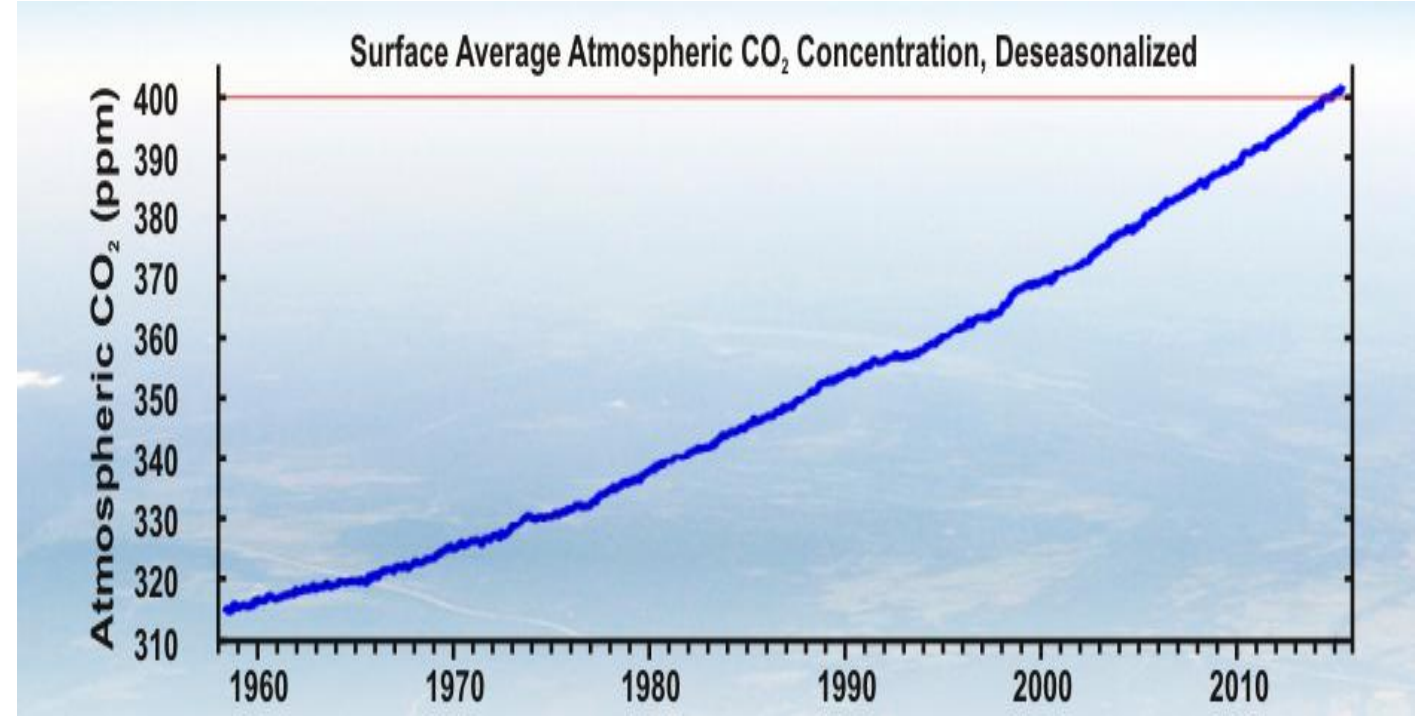

Figure 1. The atmospheric $\mathrm{CO}_{2}$ concentration during 1960-2015 (CDIAC, 2015)

The government of China reduced the environmental pollution during the Beijing APEC Summit in 2014 and on the China Victory Day parade in Beijing on September 3, 2015. These events indicate that $\mathrm{CO}_{2}$ emissions can be reduced through effective policy measures, but such efforts would require support from most people. Furthermore, enterprises must be willing to sacrifice their interests, and governments must be committed to the long-term execution of policies aimed at reducing environmental pollution and $\mathrm{CO}_{2}$ emissions.

In recent years, information technology has been integrated into the economy and society, triggering a rapid increase in data, which have consequently become the basis of China's strategical resource (State Council of the People's Republic of China, 2015). China is currently promoting applications for big data in order to stimulate economic development and promote environmental protection. Big data on energy has the 
following characteristics: high volume, wide variety, high velocity, energy, exchange, and empathy. These features not only facilitate constructing a core value chain of the Internet of energy, but also assist in optimizing the overall system and in meeting individual needs (China Report Hall, 2015). Big data could offer valuable information for practical scientific research applications, industrial and commercial development, national economic development, and issues of global concern.

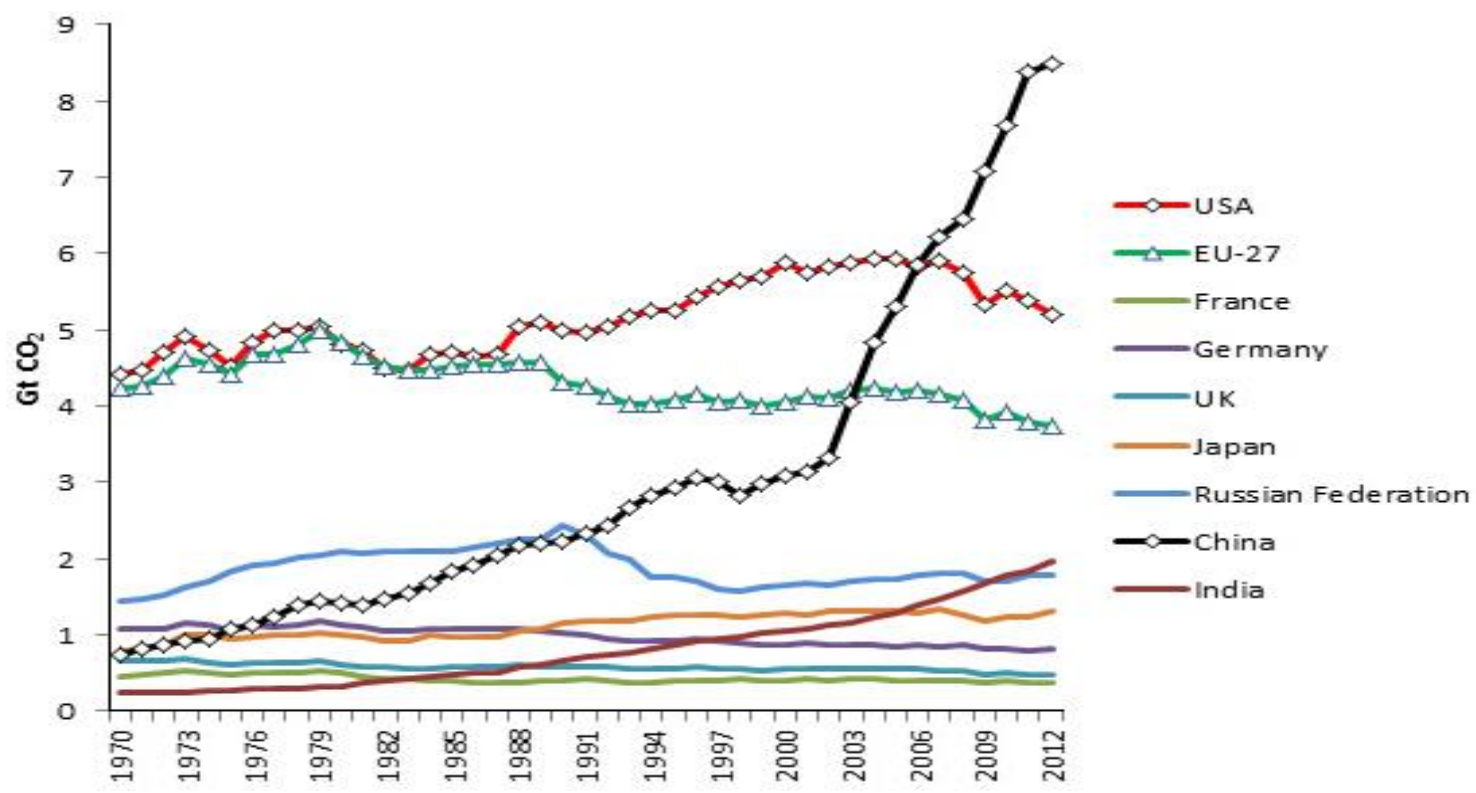

Figure 2. The $\mathrm{CO}_{2}$ emissions of major countries during 1970-2012

Moreover, the effectiveness of resolving public policy problems depends on the assistance and cooperation of citizens. Thus, community education can effectively aid the public sector in promoting policies. In recent years, the high $\mathrm{CO}_{2}$ emissions from excessive energy consumption by humans have resulted in air pollution, the greenhouse effect, global warming, climate change, and severe environmental pollution, which endangers biodiversity and human life and property. The problem of high $\mathrm{CO}_{2}$ emissions must be addressed and improved to prevent further deterioration of the global environment and catastrophic crises. An urban environment consists of diversified communities that form the basic units of local fundamental construction. However, communities are also the collective hub of energy consumption (Hsueh, 2012; Liu et al., 2014). The public buildings, public lighting equipment, private buildings, and members of communities are energy consuming normal-state aggregates. The power of community organizations and residents have a significant influence in promoting community energy-saving policies under the concepts of direction, evaluation, and subsidy, which are helpful in forming a common understanding to realize the promotional effects of community energy-saving policies. This can positively affect reducing urban air pollution.

Natural disasters are occurring more frequently than in the past, and they are becoming increasingly severe, causing greater damage than expected. Considerations of the ideal energy-saving low-carbon life style, using green energy sources, must not 
merely be a slogan or a concept, but must be fulfilled in daily life, becoming the norm, in order to slow the deterioration of our living environment. $\mathrm{CO}_{2}$ emissions can be reduced by adopting subsidy policies that encourage the use of natural energy resources in daily life. Burtraw and Parry (2011) suggested that green energy subsidies return the value of $\mathrm{CO}_{2}$ emission allowances to households. As communities are the energy consuming basic units of urban development, a widespread understanding of energy consumption within a community can use a subsidy policy to promote green energy concepts for local construction and energy-savings.

The development of green communities is conducive to enhancing environmental protection (Pîslaru et al., 2008), lowering anthropogenic $\mathrm{CO}_{2}$ (Grimmond et al., 2002), and mitigating the greenhouse effect and climate change (Pohjola and Valsta, 2007). Promoting green communities can be distinguished as energy conservation development of the entire community and energy conservation of households. Regarding the energy conservation development of the entire community, approaches that can be adopted include carbon sequetration (Benítez and Obersteiner, 2006; Lubowski et al., 2006; McKenney et al., 2004), increasing the number of plants and trees on the sides of roads and in parks in the community, and reinforcing carbon sequestration of the community to improve air quality and yield environmental benefits (Kula and Gunalay, 2012). Solar-powered devices (Wright et al., 2010; Yang et al., 2011) and LED (Jacob, 2009) can also be introduced, and solar-powered lights on community streets and solar energy devices in portions of parks can be adopted. Regarding applications for energy conservation in households, Hsueh (2012) noted that government subsidies can improve household facilities and strengthen the social responsibility of people and families, which in turn leads to energy conservation effects. Installing solar energy facilities for roofs, green roofs, LED lighting design, and water and power-saving household appliances is an effective approach for improving residences and houses. Because developing green communities requires large sums of money, it is unlikely for communities and households to receive a full subsidy from the government and see timely effects for improvement. Consequently, the current study recommends that, in addition to subsidizing the development of communities, low-interest financing channels should also be provided for green communities. By allowing areas with a high willingness to develop green communities obtain low-interest financing and higher local construction fees, these areas can immediately transfer and replace energy-saving public facilities.

To examine the effectiveness of reducing urban air pollution, this study applied the Delphi method group decision-making technique (Murry and Hammons, 1995; Ziglio and Adler, 1996) to investigate the criteria used in this study. Furthermore, the AHP multicriteria decision-making technique (Saaty, 1980; Saaty and Takizawa, 1986) was used to determine the relative importance of each criterion and the quantified function in fuzzy logic theory (Hsueh, 2012) and establish a model for quantitative assessments. A multi-criteria decision-making model (MCDM) can be employed by management departments to self-evaluate the effectiveness of policies in resolving problems or as a reference for assessing the provision of grants and low-interest financing to communities affected by policies. This model can also be employed by communities to self-review the effectiveness of community education in promoting urban air pollution reduction. 


\section{The framework of the assessment model}

The Delphi method is a research technique that was developed with implicit expert assistance and involves a high degree of professionalism and objectivity. The Delphi method was developed by the U.S. RAND Corporation to assist management in predicting future events. However, its application scope is not restricted to predicting future events (Hsueh, 2015).

The AHP method was first proposed by Saaty and has been widely used for solving multi-criteria decision-making problems. AHP is also commonly applied in social, policy, and engineering decision-making issues (Saaty, 1990; Saaty, 1994), and studies that have applied the AHP method include: Enhancing Sustainable Community Development (Hsueh and Yan, 2011), Estimation and selection of building investment (Dziadosz, 2008), Urban Renewal Proposals, Sustainable urban energy-environment management (Bose and Anandalingam, 1996) evaluation approach for livable urban environments (Chiang and Liang, 2013), sustainable water management (Freitas and Magrini, 2013), uncertainty analysis and risk assessment for sudden water pollution accidents (Hou et al., 2014), Strategic energy management (Posch et al., 2015).

Fuzzy logic theory was first proposed by Zadeh. Fuzzy logic can manage vague information in natural human language, such as uncertainty, complexity, and tolerance for imprecision (Zadeh, 1976, 1996). Fuzzy logic theory is extremely suitable for dealing with highly complex and difficult-to-quantify policy evaluations and has been applied in the following studies: especially group decision-making issues (Hadi-Vencheh and Mokhtarian, 2011; Hsueh and Huang, 2014), Sustainable and efficient energy consumption of corn production (Houshyar et al., 2012), energy consumption estimation (Istrate and Grigoraş, 2010), environmental sustainability, pretreated poultry manure wastewater (Yetilmezsoy, 2012), Fenton's strong chemical oxidation process (Sari et al., 2013), English Academic Writing (Baba et al., 2015), investigate the novel uses of nano suspended lubrication (Ooi et al., 2015), a sustainable supply chain of an apparel industry (Jakhar, 2015).

This study developed a model that combines the Delphi method, AHP, and fuzzy logic theory. This model is highly rigorous and reliable because of the expert assistance we employed to examine the content and participate in group decision-making during the modeling process. The framework of the assessment model is shown in Fig. 3. The 12 Delphi experts who assisted in this study had over 15 years practical work experience in a related field; 4 experts were from the architect, 4 were scholars, and 4public service sector. The group decision-making data collected from the Delphi experts provided the required information for a fuzzy logic model. In a DFuzzy - DAHP model environment, appropriate criteria must first be selected from the complex factors, and then each criterion hierarchy must be completed. After the quantitative natural language membership functions are selected, the fuzzy sets and fuzzy scale set, the fuzzy logic inference system (FLIS) of "IF-THEN rules base," and the DFuzzy - DAHP model can function. the Fuzzy Logic Inference System (FLIS) into four major modeling procedures, such as determining evaluation factors; defining the fuzzy set of input evaluation factors and output values; defining Membership Functions; creating IF-THEN rules; defuzzification; and exporting quantized values (Perng et al., 2005). Figure 3 is the schematic diagram of FLIS. 


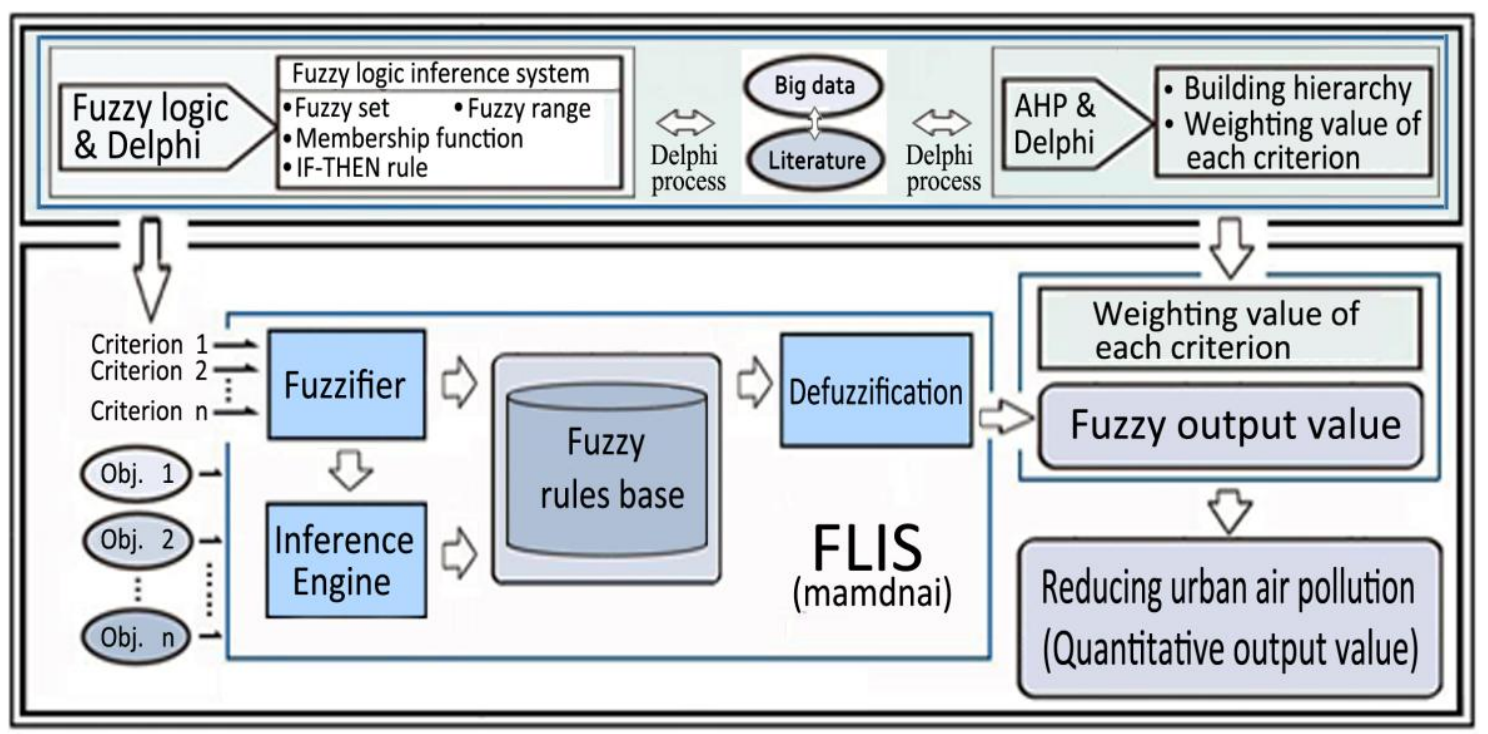

Figure 3. The framework of the assessment model

As shown in Fig. 3, this study first collected relevant literature and big data on improving air pollution in communities. This study also verified the criteria for establishing the AHP and FLIS through the Delphi process. This model is based on the knowledge of several experts and the multiattribute evaluation of big data. Its high objectivity and adaptability render its application easy to maintain, update, and use.

\section{Criteria affecting air pollution}

Developing green communities primarily requires participation from most community residents to achieve energy-saving effects. Mani et al. (2007) noted that a community's attitude and living environment are determinants of sustainability. Furthermore, developing green communities requires investment, which may come from local government subsidies, but also requires low-interest financing from banks; this facilitates the successful development of green communities. After a loan is obtained through community organizations, communities can begin solar-powered street light engineering projects and establishment of solar panels in parks and vacant areas, as well as the planting of trees. Community residents can install solar-powered or solar energy facilities or green roofs. Participation and identification from community residents and their care for tree and forest growth can lead to economic benefits from carbon sequestration and, in turn, minimize environmental pollution. In Europe, carbon is priced at $€ 20 / \mathrm{t} \mathrm{CO}_{2}$ (Lauri et al., 2012). Through carbon trading, communities would be able to generate income from carbon sequestration. Furthermore, investing in solar power energy and generation can be recouped in approximately 15 years. These measures can assist green communities in paying off interest and loans. Figure 4 illustrates the concept for developing a green community that can facilitate air pollution reduction. Vargas-Vargas et al. (2011) indicated that the relationship among economic growth, environmental sustainability, and energy are of great interest to researchers and policy makers. More diverse consideration regarding government subsidies for green 
energy would help promote green energy, and long-term low-interest loans for community development of green energy can be refunded or repaid. During the criteria investigation process for this study, Delphi experts agreed that government agencies and community residents who bear social responsibilities should agree to help rapidly complete the development of green communities through low-interest loans.

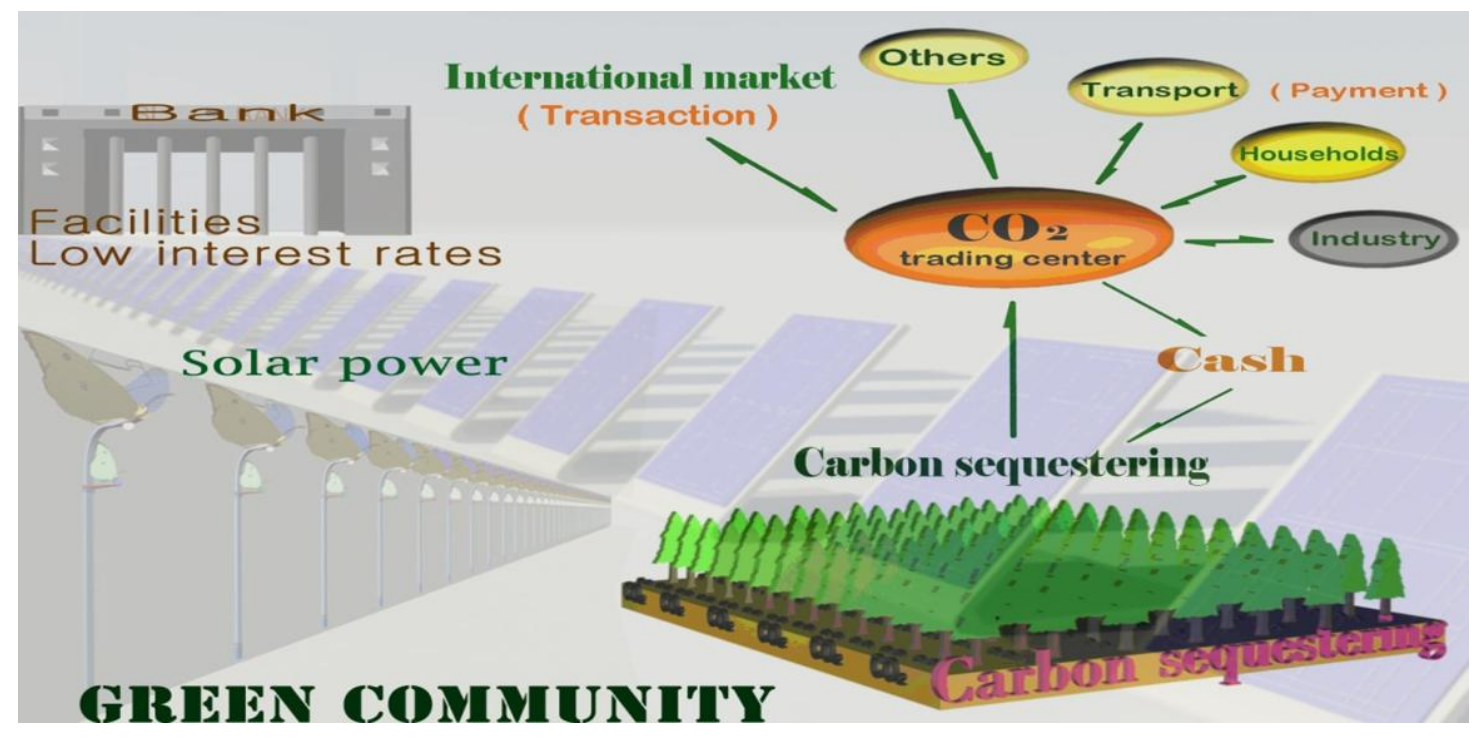

Figure 4. Development concept for a green community that enables air pollution reduction

\section{Selection of initial criteria and evaluating the weighting value}

The preliminary criteria obtained from relevant literature is related to community energy-saving solar electric systems (Black, 2004), using natural energy resources (Lam et al., 2010), resource recovery and reuse, energy-saving materials (Kotey et al., 2009; Lam et al., 2010), planning and designing energy-efficient equipment and energy-saving construction (Nishioka et al., 2000; Sailor, 2008), solar powered energy (Wright et al., 2010; Yang et al., 2011), green roofs (Sari et al., 2013), waste management (Begum et al., 2009), carbon storage in forests (Galik and Jackson, 2009; Pohjola and Valsta, 2007), and urban greening (Nishioka et al., 2000; Taylor, 2008).

According to Dr. Li Nuyun, deputy director of the General Office for Combating Climate Change within the State Forestry Administration of China and secretary general of the China Green Carbon Foundation, "Promotion of forestry carbon sequestration not only absorbs $\mathrm{CO}_{2}$ but also increases employment opportunities and income for farmers. It also helps elevate farming villages from poverty, maintains and protects biodiversity, and improves the environment, which represents multi-function forestry" (Heilongjiang, 2011). Based on an integration of the aforementioned research content, this study verified the criteria necessary for research by using the Delphi process. As shown in Table 1, each criterion in the table was agreed on by the experts. 
Table 1. Criteria jointly agreed by experts

\begin{tabular}{ll}
\hline \multicolumn{1}{c}{ Criterion } & \multicolumn{1}{c}{ Content } \\
\hline Carbon sequestration & Community planting, family planting, green roofs \\
Solar power & Solar electric systems, solar materials, solar-powered streetlights \\
Social responsibility & Resource recovery, community participation, community \\
& responsibility, low-interest financing policy \\
\hline
\end{tabular}

Through the Delphi process, the experts jointly agreed on the criteria. The big data revealed three criteria for effectively reducing air pollution in communities: carbon sequestration, solar power, and social responsibility. These three criteria were used as the basis for establishing the AHP to explore their relative weighting values, and for establishing the main input criteria of the FLIS. To explore the relative weighting value of these three criteria, we requested professionals to assist with the AHP questionnaires and obtain complete and valid questionnaire data. We adopted a strict attitude in completing the AHP process. All of the experts who assisted with the 65 valid questionnaires during the AHP process had 15 years or more work experience in their related fields. The scholars were a vice chancellor, a dean, and a senior professor at universities ranked in the top five universities in Taiwan. The industry experts were a construction, a real estate, an architect, a CEO, and a project manager with a master's degree. The majority of the government officials also had master's degrees and were all also family members. This study was conducted from October 2012 to Aug 2013 to complete the AHP process. Table 2 shows the relative weight calculations for each criterion in the overall assessment. The AHP calculation process must adhere to a consistency test consisting of two indices, namely, the consistency index (CI) and the consistency ratio $(\mathrm{CR})$. For the $\mathrm{CI}, 0$ denotes that the survey data are consistent, 1 denotes that the data are erroneous, and $\leq 1$ denotes that the data are within an acceptable margin of error. For the $\mathrm{CR}, \leq 0.1$ denotes that the survey data are consistent. Therefore, AHP calculation results must correspond to both indices to enable subsequent weighting values to be reference values.

Table 2. Weighting value of criteria

\begin{tabular}{|c|c|c|c|}
\hline \multicolumn{4}{|c|}{ Comparison of Carbon sequestration, Solar powered and Social responsibility } \\
\hline Criteria & Relative weight & Weighting value & Consistency test \\
\hline Carbon sequestration & 1 & 0.09 & C.I. $=0.03$ \\
\hline Solar powered & 4 & 0.27 & C.R. $=0.05 \leqq 0.1$ \\
\hline Social responsibility & 6 & 0.64 & \\
\hline Note & \multicolumn{3}{|c|}{$\begin{array}{l}\text { 1. Relative importance is categorized into } 10 \text { levels. The AHP survey } \\
\text { results included the relative importance of three criteria. } \\
\text { 2. The mean value of the effective survey data was adopted as the } \\
\text { comparison value for the relative importance of the three criteria. }\end{array}$} \\
\hline
\end{tabular}




\section{Defining input and output membership function - fuzzy set of each criterion}

Before establishing the FLIS system, the definitions of the membership function, fuzzy set, fuzzy range of each criterion (including the definition of the membership function and fuzzy range for the fuzzy set of the output value) must be established. When defining the fuzzy quantification of each evaluation criterion or factor, the IF-THEN rule base of the FLIS system is adopted for a proper quantification of assessment problems or topics in different scenarios. As different assessment criteria exert various influences on green community development effectiveness evaluations, the definitions of membership function, fuzzy set, and fuzzy range must be established. Thus, different input scenarios can be input through the IF-THEN rule base to complete linguistic variable calculation and inference (Zadeh, 1975), and the corresponding output evaluation results can be presented. Figure 5 illustrates the fuzzy set and fuzzy range definitions of three criteria, as well as the fuzzy set and fuzzy logic definitions of corresponding output values. The definition measurement scale in fuzzy logic is an artificial fuzzy scale. For instance, a profit of $90 \%$ in carbon sequestration is very good," $60 \%$ is ordinary," and $30 \%$ is very poor." However, whether $75 \%$ is good or ordinary is defined according to membership function in the fuzzy logic scale; through the defuzzification of FLIS, the quantified output result can be presented. This is one of the problems that traditional evaluation models can process only with great difficulty.

The evaluation subject is quantized by using different degree values in the fuzzy set when calculating the fuzzy quantized values of three evaluation factors, such as carbon sequestration, solar power, and social responsibility. Because different evaluation factors have different effects on the evaluation of community energy saving, only the range definition of the fuzzy set can present the output evaluation result. A triangular membership function (Fig. 6) was employed in the present study. Figure 4 shows that when the $x$ value is between $a$ and $b$, the degree of membership of $x$ in Set A cannot be 0 . When $x$ shifts closer to $m$, the degree of membership of $x$ increases. When the $x$ value reaches $m, x$ achieves maximum membership in Set A with a value of 1 .

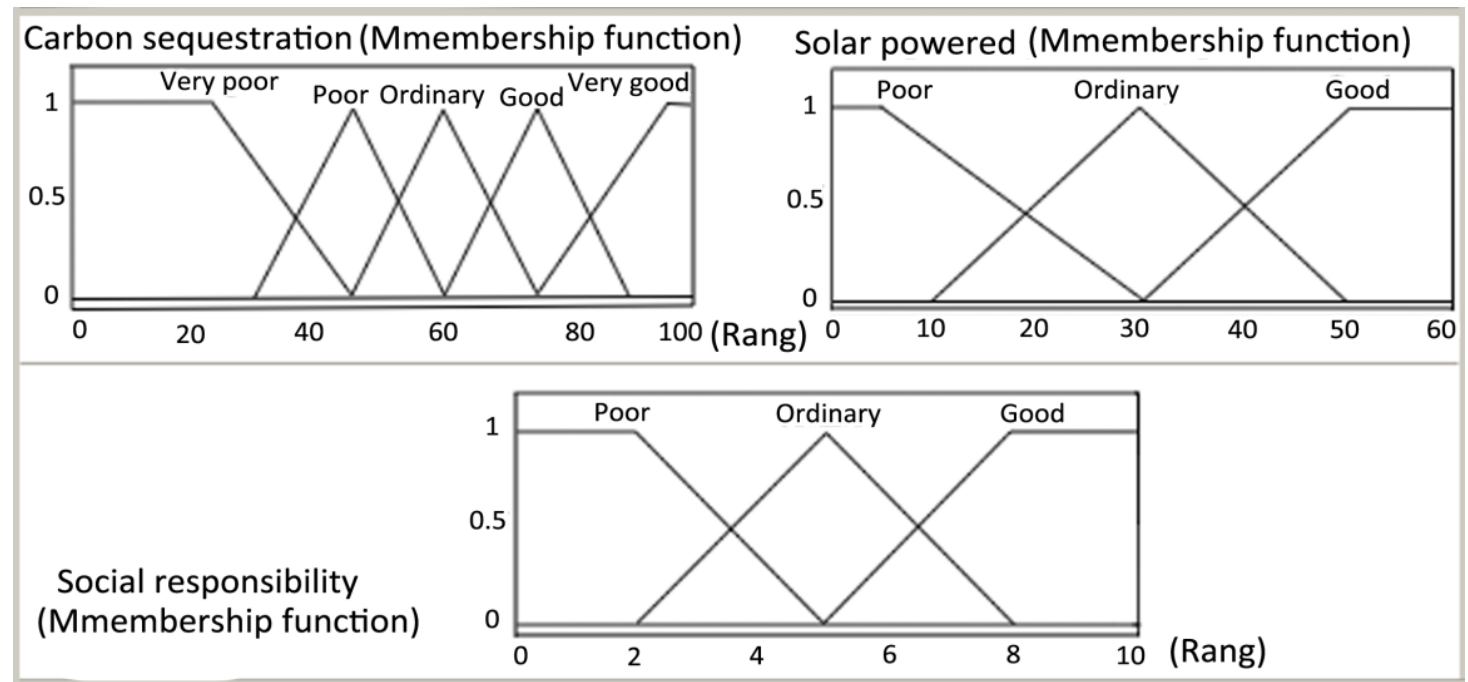

Figure 5. Membership function, fuzzy set and range definitions of input 


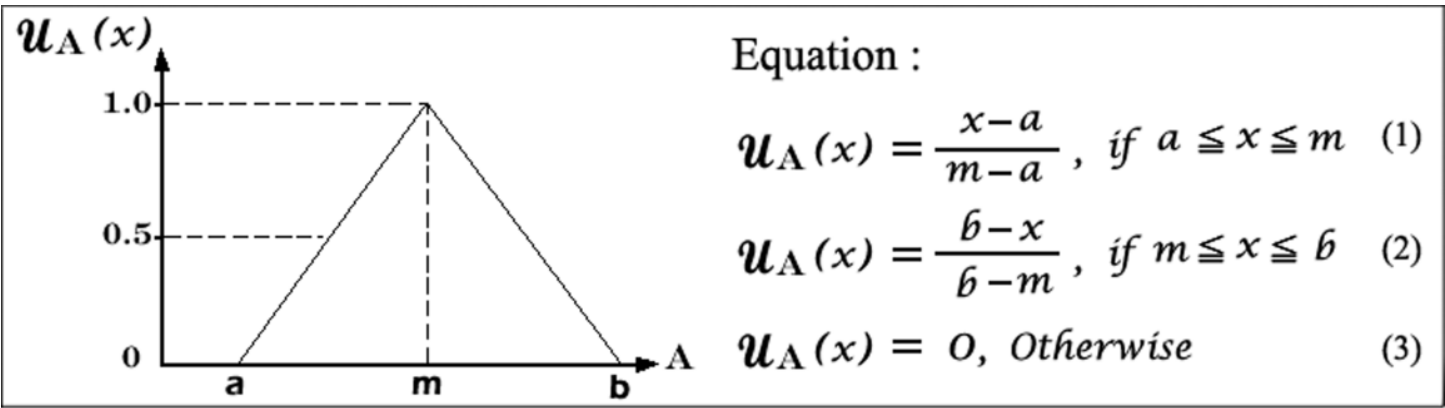

Figure 6. Triangular membership function

\section{Input scenario and output mapping}

After input scenarios are entered into the FLIS system and processed through the IF-THEN rule base inferences, the results are defuzzified and are output as a single quantified value. There are 45 input scenarios in the current model, with three criteria: carbon sequestration, solar power, and social responsibility. Among them, five fuzzy sets are under carbon sequestration and the fuzzy evaluation scenarios include "very good," "good," "ordinary," "poor," and "very poor." Moreover, three fuzzy sets are under solar power and social responsibility, resulting in a total of 45 scenarios. Each criterion of the scenarios has a different level of influence on the evaluation of the effectiveness of green community development. The 45 evaluation scenarios are composed of distinct measurement units with multiple attributes that include the ability to process complex evaluation problems. Figure 7 presents the 3D mapping relationships of the input scenarios and outputs for three criteria. This is a computation model that is difficult to achieve artificially or through human development. Moreover, within the overall FLIS, the fuzzy rule base is akin to the human brain. When the FLIS inference rules are established, the FLIS can perform the function of inference and computation. If each evaluation factor is assigned an input value by the decision maker, then the FLIS can automatically calculate the quantified evaluation value of the effectiveness.

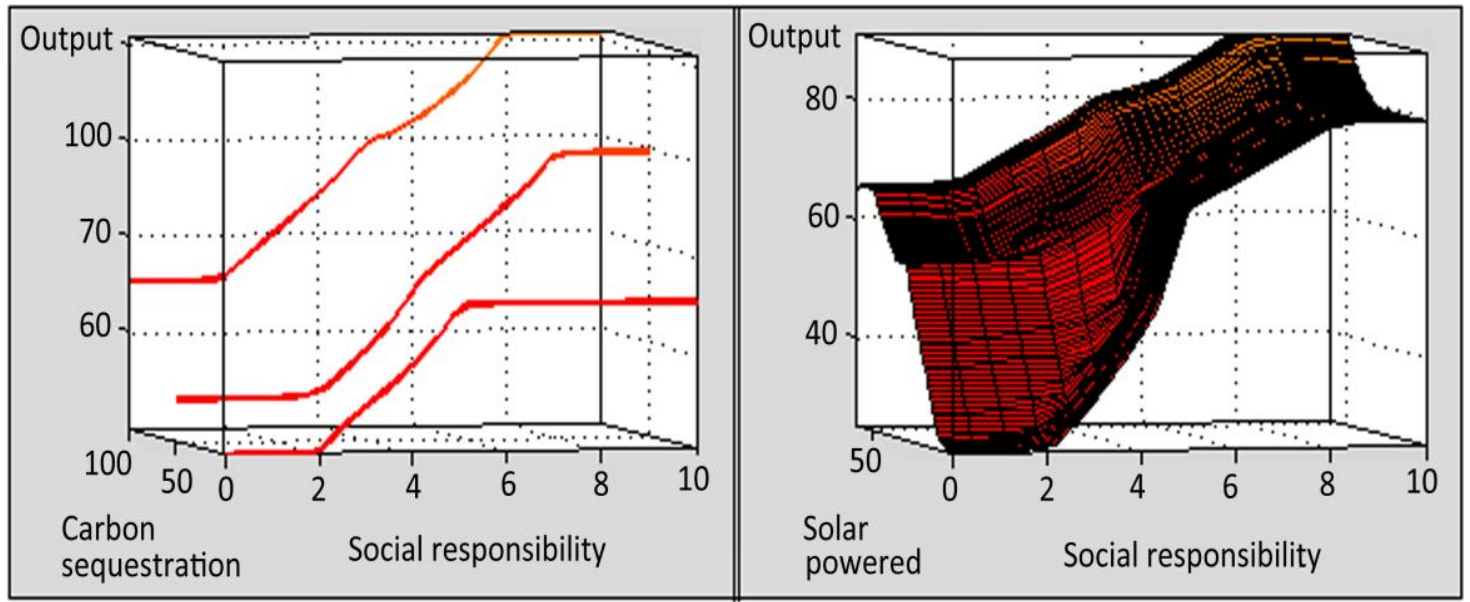

Figure 7. 3D mapping relationships among the input scenarios and output 
Table 3 lists the optimal and poorest quantified output values calculated by using the FLIS. The input scenario in Table 3 can be a quantified value or a fuzzy meaning in natural language, such as "good" (high), "ordinary" (medium), and "not good or poor" (low). This is because fuzzy logic bears the function of calculating the linguistic variables and making inferences for linguistic quantification (Zadeh, 1975, 1976). The current model serves as a reference for decision makers prior to project evaluation. By performing accurate and scientific calculation, an additional comparison of the quantified values can become the basis for decisions, thus contributing to the efficiency and effectiveness of the decision-making process and lowering the risks of making poor or incorrect decisions.

Table 3. Optimal and worst output value

\begin{tabular}{lll}
\hline Criteria & Optimal & Worst \\
\hline Carbon sequestration & Very good & Very poor \\
Solar power & Good & Poor \\
Social responsibility & Good & Poor \\
Output value $(\%)$ & 91.0 & 20.9 \\
\hline
\end{tabular}

\section{Case study}

The fuzzy quantified output value obtained using the FLIS shows the superiority or inferiority of community environmental protection education promotion. If expressed with yi, then calculating (yi * wi) demonstrates the latent importance of each criterion, allowing decision makers to easily obtain decision-making information. The community in Case 1 has more space for planting trees and should produce higher carbon sequestration than its counterpart in Case 2. However, the model shows the opposite effect, the community in Case 2 possesses a higher carbon sequestration evaluation. In Table 4, the latent influence of each criterion in Case 2 shows that the community has not only higher carbon sequestration but higher social responsibility. The present case study verifies that participation from community residents is conductive to and has value-added effects for developing a green community. Thus, overall, the community in Case 2 exerted a significant effect on reducing air pollution. In addition, the promotion of community environmental protection education was more favorable in Case 2, and community residents placed a higher amount of emphasis on improving air quality.

The DAHP-Dfuzzy quantitative model was employed to convert 45 input scenarios into a schematic calculation diagram involving the quantified output values (Fig. 8).

Table 4. Case 1 and Case 2

\begin{tabular}{llcclcc}
\hline Criteria (wi) & Case 1 & \multicolumn{5}{c}{ Case 2 } \\
\cline { 2 - 7 } & Scenario & yi & yi* wi & scenario & yi & yi * wi \\
\hline Carbon sequestration (0.09) & Very good & 63.3 & 5.679 & Good & 82 & 7.38 \\
Solar power (0.27) & Ordinary & & 17.091 & Good & 22.14 \\
Social responsibility (0.64) & Ordinary & & 40.512 & Good & 52.48 \\
\hline
\end{tabular}




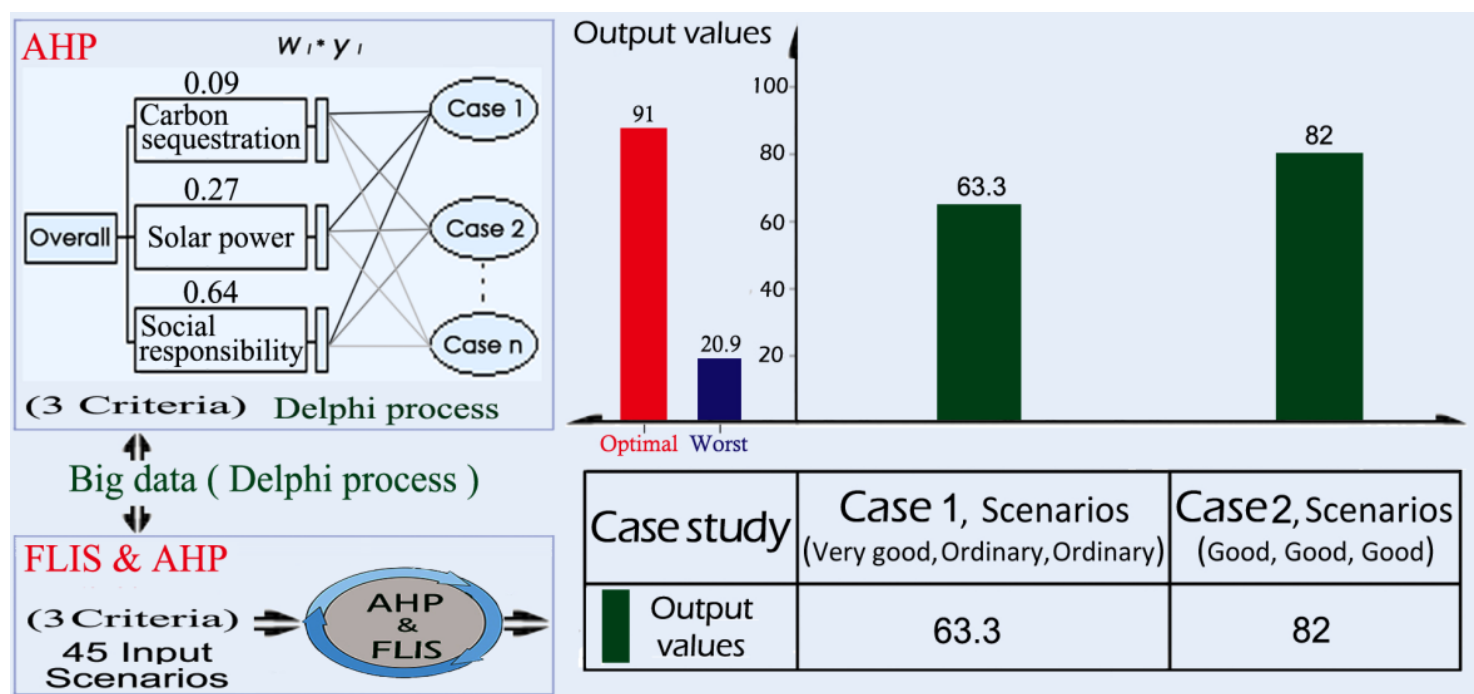

Figure 8. Input and output calculations of the DAHP-Dfuzzy quantitative model

As shown in Fig. 8, this study determined through the Delphi process that the three criteria in the big data influenced the air quality of communities. Their weighting values for carbon sequestration, solar power, and social responsibility are $0.09,0.27$, and 0.64 , respectively. The weighting value of carbon sequestration is particularly low, whereas that of social responsibility is particularly high. This shows that the community residents demonstrated a high level of care about the quality of air in their community, but they did not display a high level of willingness for plain afforestation. The results of both cases indicate that the community residents in Case 1 supported plain afforestation, but the overall assessment did not produce a beneficial result because the community lacked the funds and human resources for maintaining and managing the planted trees. This finding may serve as a reference for revising policies regarding plain afforestation and for improving the effectiveness of such policies.

Big data provide critical information from various fields. The effective application of big data creates a virtuous cycle with added-value. It also facilitates uncovering issues and exploring the source of a problem, thereby solving rooted difficult problems. This study verified the criteria for establishing an MCDM model from big data through using the Delphi process. The proposed quantitative evaluation model is not only enables assessing the impact of a single community on air pollution, but it also enables assessing and comparing the positive and negative effects of different communities. The final result could serve as a reference for governmental departments, and could be sent as feedback to the archives of big data for further application.

\section{Suggestions and conclusion}

\section{Suggestions}

When a new policy is promoted, active participation by the public enhances the effectiveness of its implementation. The study found that although the communities accepted plain afforestation, it could not achieve the expected effect because of a lack of 
community funds. To ensure that plain afforestation achieves carbon sequestration, thereby improving community air quality, this study proposes two suggestions: (1) offer low interest rates (prime rate) for idle land in communities; (2) establish an emissions trading scheme for carbon sequestration. Accordingly, the public would be required to pay for both the energy they consume and the carbon pollution they generate. Simultaneously, community residents and groups who are keen on promoting plain afforestation can use the payment for funding the long-term maintenance of tree plantations.

\section{Conclusion}

Various big data have continued to accumulated, changing the environment in the process of social development. Today, global warming, climate change, and disasters affecting biological diversity are not accidental events. Big data show that the problem of high $\mathrm{CO}_{2}$ emissions is caused by the long-term excessive use of energy by humans. The analysis of big data and application of derived information would facilitate investigating the fundamental factors of environmental pollution, and would also assist in proposing effective solutions. Community education and promotion aids residents in understanding the importance of public policies and enhances their participation in resolving problems related to such policies. In recent years, industrial development has caused extreme energy consumption and emission of large amounts of greenhouse gases, polluting the environment and causing abnormal climate changes that increasingly threaten human life and property. If the cap-and-trade rules remain unable to restrain human materialistic needs, green efforts exerted will not conspicuously reduce the rate and influence of $\mathrm{CO}_{2}$ emissions. The evaluation model for reducing urban air pollution established in this study incorporates green community development, social responsibility, and low-interest financing, and can be used to assess community residents' participation and acceptance and to motivate developing the habit of caring for the environment. In addition, fuzzy logic includes artificial intelligence functions, and when combined with the AHP model, it can enable decision-makers to comprehend the relative importance of factors influencing decision-making for complex topics. Moreover, the concerns to be assessed can be converted to numbers or proportions that are easily understood. The developed model is a scientifically derived set of objective quantitative assessment model that can facilitate comprehensively assessing the latent factors of a topic and promoting the development of urban air pollution reduction plans.

Acknowledgements. We thank the Dahu Community in Kaohsiung City for funding this study on community afforestation (Zihao-Dahu Community-Mei Zihao-100122) and providing relevant research assistance.

\section{REFERENCES}

[1] Baba, A. F., Melis Cin, F., Ordukaya, E. (2015): Intelligent fuzzy assessment system for English academic writing in engineering education. - International Journal of Engineering Studies 31: 83-93.

[2] Begum, R. A., Siwar, C., Pereira, J. J., Jaafar, A. H. (2009): Attitude and behavioral factors in waste management in the construction industry of Malaysia. - Resources, 
Conservation and Recycling 53: 321-328.

http://dx.doi.org/10.1016/j.resconrec.2009.01.005

[3] Benítez, P. C., Obersteiner, M. (2006): Site identification for carbon sequestration in Latin America: A grid-based economic approach. - Forest Ecology and Management 8: 636-651. http://dx.doi.org/10.1016/j.forpol.2004.12.003

[4] Black, A. J. (2004): Financial payback on California residential solar electric systems. Solar Energy 77: 381-388. http://dx.doi.org/10.1016/j.solener.2004.02.003

[5] Bose, R. K., Anandalingam, A. (1996): Sustainable urban energy-environment management with multiple objectives. - Energy 21: 305-318. http://dx.doi.org/10.1016/0360-5442(95)00098-4

[6] Burtraw, D., Parry, I. W. H. (2011): Options for returning the value of $\mathrm{CO}_{2}$ emissions allowances to households. - Resources for the Future 11-03. http://dx.doi.org/10.2139/ssrn.1767411

[7] CDIAC. 2015: http://cdiac.ornl.gov/. Access date: August 2015.

[8] Chiang, C. L., Liang, J. J. (2013): An evaluation approach for livable urban environments. - Environmental Science and Pollution Research 20: 5229-5242. http://dx.doi.org/10.1007/s11356-013-1511-6

[9] Bureau of Foreign Trade, State Council of the People's Republic of China. 2015: Action Plan to Promote Big Data Development. Xinhua News Agency.

http://www.trade.gov.tw/World/Detail.aspx ?nodeID=45\&pid=534683. Access date: 19 September 2015.

[10] China Reports Hall. (2015): 2015 Analysis of new energy industries: Internet finance and innovation. http://big5.chinabgao.com/freereport/67916.html. Access date: 19 September 2015.

[11] Dziadosz, A. (2008): Estimation and selection of building investment using AHP. Czasopismo Techniczne 1-B2: 41-51.

[12] Freitas, A. H. A., Magrini, A. (2013): Multi-criteria decision-making to support sustainable water management in a mining complex in Brazil. - Journal of Cleaner Production 47: 118-128. http://dx. doi:10.1016/j.jclepro.2012.10.043.

[13] Galik, C. S., Jackson, R. B. (2009): Risks to forest carbon offset projects in a changing climate. - Forest Policy and Economics 257: 2209-2216. http://dx.doi.org/10.1016/j.foreco.2009.03.017.

[14] Grimmond, C. S. B., King, T. S., Gropley, F. P., Nowak, D. J., Souch, C. (2002): Local scale fluxes of carbon dioxide in urban environments: methodological challenge and results from Chicago. - Environmental Pollution 116: S243-S254. http://dx.doi.org/10.1016/S0269-7491(01)00256-1.

[15] Hadi-Vencheh, A., Mokhtarian, M. N. (2011): A new fuzzy MCDM approach based on centroid of fuzzy numbers. - Expert Systems with Applications 38: 5226-5230. http://dx.doi.org/10.1016/j.eswa.2010.10.036.

[16] Heilongjiang, E. N. (2011): Carbon economy: Forestry - New Highlights. http://www.greentimes.com/green/econo/tanhui/thzx/content/2011-04/26/content_128393 .htm. Access date: 30 December 2014.

[17] Hou, D., Ge, X., Huang, P., Zhang, G., Loáiciga, H. (2014): A real-time, dynamic early-warning model based on uncertainty analysis and risk assessment for sudden water pollution accidents. - Environmental Science and Pollution Research 21: 8878-8892. http://dx.doi.org/10.1007/s11356-014-2936-2.

[18] Houshyar, E., Azadi, H., Almassi, M. (2012): Sustainable and efficient energy consumption of corn production in Southwest Iran: Combination of multi-fuzzy and DEA modelling. - Energy 44: 672-681. http://dx.doi.org/10.1016/j.energy.2012.05.025

[19] Hsueh, S. L, Huang, C. H. (2014): Using fuzzy multi-criteria assessment model for evaluating student's core competencies-a view of cultural and creative design 
education. - International Journal of Engineering Education 30: 276-282.

[20] Hsueh, S. L. (2012): A fuzzy utility-based multi-criteria model for evaluating households' energy conservation performance: a Taiwanese case study. - Energies 5: 2818-2834. http://dx.doi.org/10.3390/en5082818

[21] Hsueh, S. L. (2015): Assessing the effectiveness of community-promoted environmental protection policy by using a Delphi-fuzzy method: A case study on solar power and plain afforestation in Taiwan. - Renewable and Sustainable Energy Reviews 49: 1286-1295. http://dx.doi.org/10.1016/j.rser.2015.05.008

[22] Istrate, M., Grigoraş, G. (2010): Energy consumption estimation in water distribution systems using fuzzy techniques. - Environmental Engineering and Management Journal 9: 249-256.

[23] Jacob, B. (2009): Lamps for improving the energy efficiency of domestic lighting. Lighting Research \& Technology 41: 219-228. http://dx.doi.org/10.1177/1477153509339610

[24] Jakhar, S. K. (2015): Performance evaluation and a flow allocation decision model for a sustainable supply chain of an apparel industry. - Journal of Cleaner Production 87: 391-413. http://dx.doi:10.1016/j.jclepro.2014.09.089

[25] Kotey, N. A., Wright, J. L. Barnaby, C. S., Collins, M. R. (2009): Solar gain through windows with shading devices: simulation versus measurement. - ASHRAE Transactions 115: 18-30.

[26] Kula, E., Gunalay, Y. (2012): Carbon sequestration, optimum forest rotation and their environmental impact. - Environmental Impact Assessment Review 37: 18-22. http://dx.doi.org/10.1016/j.eiar.2011.08.007

[27] Lam, T. I., Chan, H. W., Poon, C. S., Chau, C. K., Chun, K. P. (2010): Factors affecting the implementation of green specifications in construction. - Journal of Environmental Management 91: 654-661. http://dx.doi.org/10.1016/j.jenvman.2009.09.029

[28] Lauri, P., Kallio, A. M. I., Schneider, U. A. (2012): Price of $\mathrm{CO}_{2}$ emissions and use of wood in Europe. - Forest Policy and Economics 15: 123-131. http://dx.doi.org/10.1016/j.forpol.2011.10.003

[29] Liu, K. S., Liao, Y. T., Tzeng, C. T. (2014): TBEE model for green design courses to evaluate the indoor environment health of existing buildings in Taiwan. - International Journal of Engineering Education 30: 283-290.

[30] Liu, Z. (2015): China's Carbon Emissions Report 2015. Sustainability Science Program and Energy Technology Innovation Policy research group, Belfer Center Discussion Paper \#2015-02. Harvard Kennedy School of Government, Cambridge, MA.

[31] Lubowski, R. N., Plantinga, A. J., Stavins, R. N. (2006): Land-use change and carbon sinks: econometric estimation of the carbon sequestration supply function. - Journal of Environmental Economics and Management 51: 135-152. http://dx.doi.org/10.1016/j.jeem.2005.08.001

[32] Mani, M., Varghese, K., Ganesh, L. S. (2007): Sustainability evaluation of an urban residential settlement. - Environmental Engineering and Management Journal 6: 189-203.

[33] McKenney, D. W., Yemshanov, D., Fox, G., Ramlal, E. (2004): Cost estimates for carbon sequestration from fast growing poplar plantations in Canada. - Forest Ecology and Management 6: 345-358. http://dx.doi.org/10.1016/j.forpol.2004.03.010

[34] Murry, J. W., Hammons, J. O. Jr. (1995): Delphi: A versatile methodology for conducting qualitative research. - Review of Higher Education 18: 423-436.

[35] Nishioka, Y., Yanagisawa, Y., Spengler, J. D. (2000): Saving energy versus saving materials. - Journal of Industrial Ecology 4: 119-135.

http://dx.doi.org/10.1162/108819800569212

[36] Ooi, M. E., Sayuti, M., Sarhan, A. A. D. (2012): Fuzzy logic-based approach to 
investigate the novel uses of nano suspended lubrication in precise machining of aerospace AL tempered grade 6061. - Journal of Cleaner Production 89: 286-295. http://dx. doi:10.1016/j.jclepro.2014.11.006

[37] Perng, Y. H., Hsueh, S. L., Yan, M. R. (2005): Evaluation of housing construction strategies in China using fuzzy-logic system. - International Journal of Strategic Property Management 9: 215-232. http://dx.doi.org/10.1080/1648715X.2005.9637538

[38] Pîslaru, M., Avasilcăi, S., Trandabăţ, A. (2008): Environmental sustainability based on fuzzy models. - Environmental Engineering and Management Journal 7: 25-29.

[39] Pohjola, J., Valsta, L. (2007): Carbon credits and management of Scots pine and Norway spruce stands in Finland. - Forest Policy and Economics 9: 789-798.

http://dx.doi.org/10.1016/j.forpol.2006.03.012

[40] Posch, A., Brudermann, T., Braschel, N., Gabriel, M. (2015): Strategic energy management in energy-intensive enterprises: A quantitative analysis of relevant factors in the Austrian paper and pulp industry. - Journal of Cleaner Production 90: 291-299.http://dx.doi:10.1016/j.jclepro.2014.11.044

[41] Saaty, T. L. (1980): The Analytical Hierarchy Process: Planning, Priority Setting, Resource Allocation. McGraw-Hill Book Co, New York.

[42] Saaty, T. L. (1990): How to make a decision: the analytic hierarchy process. - European Journal of Operational Research 48: 9-26. http://dx.doi.org/10.1016/0377-2217(90)90057-I

[43] Saaty, T. L. (1994): How to make a decision: the analytic hierarchy process. - Interfaces 24: 19-43. http://dx.doi.org/10.1287/inte.24.6.19

[44] Saaty, T. L., Takizawa, M. (1986): Dependence and independence: From linear hierarchies to nonlinear networks. - European Journal of Operational Research 26: 229-237. http://dx.doi.org/10.1016/0377-2217(86)90184-0

[45] Sailor, D. J. (2008): A green roof model for building energy simulation programs. Energy and Buildings 40: 1466-1478. http://dx.doi.org/10.1016/j.enbuild.2008.02.001

[46] Sari, H., Yetilmezsoy, K., Ilhan, F., Yazici, S., Kurt, U., Apaydin, O. (2013): Fuzzy-logic modeling of Fenton's strong chemical oxidation process treating three types of landfill leachates. - Environmental Science and Pollution Research 20: 4235-4253. http://dx.doi.org/10.1007/s11356-012-1370-6

[47] Taylor, R. (2008): Green roofs turn cities upside down. - ECOS Magazine 143: 18-21.

[48] Vargas-Vargas, M., Mondéjar-Jiménez, J., Montero-Lorenzo, J. M., Fernández-Avilés, G. (2011): Per Capita $\mathrm{CO}_{2}$ Emission trends among European OECD countries. Environmental Engineering and Management Journal 10: 1865-1871.

[49] Wright, C., Baur, S., Grantham, K., Stone, R. B., Grasman, S. E. (2010): Residential energy performance metrics. - Energies 3: 1194-1211. http://dx.doi.org/10.3390/en3061194

[50] Yang, Z., Wang, Y., Zhu, L. (2011): Building space heating with a solar-assisted heat pump using roof-integrated solar collectors. - Energies 4: 504-516. http://dx.doi.org/10.3390/en4030504

[51] Yetilmezsoy, K. (2012): Fuzzy-logic modeling of Fenton's oxidation of anaerobically pretreated poultry manure wastewater. - Environmental Science and Pollution Research 19: 2227-2237. http://dx.doi.org/10.1007/s11356-011-0726-7

[52] Zadeh, L. A. (1975): The concept of a linguistic variable and its application to approximate reasoning - III. - Information Sciences 9: 43-80. http://dx.doi.org/10.1016/0020-0255(75)90017-1

[53] Zadeh, L. A. (1976): A fuzzy-algorithmic approach to the definition of complex or imprecise concepts. - International Journal of Man-Machine Studies 8: 249-291. http://dx.doi.org/10.1016/S0020-7373(76)80001-6 
[54] Zadeh, L. A. (1996): Fuzzy logic = computing with words. - IEEE Xplore: IEEE Transactions on Fuzzy Systems 4: 103-111. http://dx.doi.org/10.1109/91.493904

[55] Ziglio, E., Adler, M. (1996): Gazing into the Oracle: The Delphi Method and its Application to Social Policy and Public Health. - Jessica kingsley, London, UK, pp. 1-33. 